\title{
Light and Dark Hero in a Playing City: An Interactive and Multivariate Methodology for Predicting the Architecture of the Future
}

\author{
Anna V. Solovieva ${ }^{1, *}$ Egor A. Orlov $^{1, a}$ Tatiana S. Semichevskaya ${ }^{1, b}$ \\ ${ }^{I}$ Department of Architecture and civil engineering, Peoples' Friendship University of Russia (RUDN \\ University), Moscow, Russia \\ ${ }^{a}$ Email: egororlovrus@gmail.com \\ ${ }^{b}$ Email: t.semichevskaya@gmail.com \\ *Corresponding author. Email: solovyeva-anv@rudn.ru
}

\begin{abstract}
The authors offer the concept of interactive and multivariate forecasting of the city of the future. The main genre as part of an alternative forecast is proposed - a game architectural utopia. Its functions, properties, and categories are analyzed, the fundamental role of the architect in the process of designing interactive architectural foresight is revealed. The authors introduce the concept of a "Light" and "Dark" architectural superhero in the game utopia. In the article, the authors explore a new approach to the architectural forecasting of the city of the future, which is based on the principles of computer games. The main role of an architect is revealed, who acts as a hero of a film or a computer game, creating a living game future by his actions. At the end of the article, two polarities of the architectural utopia of the 21 st century were proposed: the virtual and physical space of the game. Using a synergistic approach, the authors introduce a new concept - game architectural utopia, as a theorem of multivariate and interactive forecasting.
\end{abstract}

Keywords: Utopia, Playing space, Forecasting, City of the future.

\section{INTRODUCTION}

The architectural utopia of the 21 st century begins to experiment with concepts of the future. It uses various alternative forecasting mechanisms based on the principles of multivariance. Instead of a linear "vector" model of time, it discovers technologies for random and game modelling of the future. Moreover, it raises the question of the "reality" of the versions invented by the architect. For inspiration, it draws on ideas from contemporary cinema and video games. Such movies as The Terminator (1984), Dark (2017), Looper (2012), Black Mirror: Bandersnatch (2018), Back to the Future (1985), Twelve Monkeys (1995), Edge of Tomorrow (2014), Groundhog Day (1993), Interstellar (2014), Arrival (2016), Minority Report (2002) and series of Doctor Who (1963-2020) suggest how else one can look and experiment with the future. Despite the idea of "time travel" is not new - you can remember the novels of H.G. Wells, today things are completely different. If earlier the main goal of such utopian projects was to demonstrate the "distant image" of the future and travel to it using a time machine, today it is the idea of the variability and uncertainty of the concept of time itself [1]. For example, instead of arranging events in a strict sequence based on cause-and-effect relationships, architectural utopias use the method of randomness, asynchrony, and polytemporality when the future does not have to follow the present, but the past must remain unchanged and be behind us. Many modern architectural theories adopt alternative models of forecasting the future and create not "exact", but "possible and random" variants. You can call them "parallel versions" which do not have to happen, most likely they will remain potential events that have arisen somewhere in "one of" your invented parallel universes. That is why the author proposes to abandon the concept of "image of the future" and use the concept of "parallel realities" 
which most accurately actualizes the modern approach in forecasting theory. This approach opens the opportunity for the architect to get inside the future and live all its versions in unlimited quantities. Like the heroes of the famous sci-fi ironic series Rick and Morty (2013) who jump from one reality to another in every new episode. For example, in one of the episodes, the main characters get into a "virtual simulation" that turns on and off all possible endings of the cartoon. The "time machine" itself is represented here in the form of a toy train moving in an unknown direction, inside which our heroes find themselves. Visitors play in it a kind of endless computer game, changing the plot of the film itself and breaking the static picture of time. In this sense the main question regarding the project of the future is not "when it happened" but in "which of the parallel realities". Such a conceptual twist can be characterized as an appeal to the play potential of an architectural utopia: an architect creates a fictional play universe, within which he can generate different scenarios, thereby undermining the basic concept of time in forecasting theory. In other words, the architecture of the future at the beginning of the new century first began to turn to playful and interactive forecasting models.

In this study, we propose to take a closer look at the modern approach to predicting the future and the concept of time using the example of $21 \mathrm{st}-$ century cinema. For example, in the Marvel Universe in the movie Watchmen (2009) there is a character Dr. Manhattan who lives in the past, present, and future at the same time. Time for him flows differently than for us - he can commit an act in the future, however, start talking about it in the past before the moment of the event. He lives simultaneously in all moments at once, knows everything, and cannot change anything and therefore constantly indulges in sadness in complete solitude on Mars without trying to alter something. In the movie Terminator (1984) we are offered the concept where time is "multivariate", not static and "modulated" and therefore the past can be easily changed from the future. For this, there are terminators - humanoid machines (serial brand T-800) made of liquid metal sent from the future to the present to disrupt the course of things. A kind of "paradox of time" is embodied in the idea of an eternal "time loop" when an object moves from the future to the past, thereby creating an endless loop of time, in which the origin of this object can no longer be traced - it seems to exist but it still nobody created, as in the unsolvable problem of "chicken and egg". Everything rests not on the idea of a beginning or an end but the question "does this object exist at all". In the interactive film Black Mirror: Bandersnatch (2018) the protagonist creates a computer game, however soon he realizes that he is its character whose actions are completely controlled by the viewer. Thus, the character of the film gets the opportunity to "replay" the most important moments of his life to achieve the best result: by the way, at one point you will even have the opportunity to hint to your character in the movie that he is a character controlled by you, and his actions and life is just a computer game. In the movie Groundhog Day (1993) the hero gets into a time loop and every day chooses a different sequence of actions, generating options for an individual future, however at the end of the day he starts all over again living one big déjà vu as in the "eternal return" by Nietzsche. Finally, in the movie Dark (2017), the main character opens the opportunity to travel in time and learns that all his acquaintances around are in fact "himself in different periods of multivariate time."

Thus, with the beginning of the 21st century, a new trend is emerging in the field of cinema, video games, art, and architecture regarding the way of predicting the future. Forecasting for the first time begins to be understood as an interactive and multivariate process, not limited to just one version of the future. Forecasting is thought of as a game technology, the ending of which is never determined in advance and depends entirely on the choice of the protagonist's actions. This allows different architects to create different game realities. Both realities may never intersect with each other if the architects themselves do not want to, but they are all "real". This determines different ends of the future for different choices. As a response to this approach to understanding the future, new forecasting methods are emerging in the architectural industry based on the principles of randomness, variance, communication, performance, randomness, and playfulness. Architects today create "versions of parallel realities" and not one single "picture" of the future.

Problems: The main problem of architectural utopia is a static and ideal image of the future, which deprives the architect of the ability to influence and change foresight.

Targets and goals: The article analyses alternative technologies for forecasting the city of the future. The hypothesis of an interactive and 
multivariate method of architectural forecasting is proposed.

\section{SIMULATION OF THE CITY OF THE FUTURE. READY PLAYER ONE}

The main genre of the new interactive architectural forecasting is virtual utopia.

Virtuality (from Latin virtualis - possible) is an object that does not exist, an eternal potentiality that is never fully embodied. In the modern sense, this is a state in which the subject loses the distinction between the real and the constructed (virtual) world. Instead of one single version of the world, he refers to numerous constructed versions of reality. In this regard, the author gives the following definition of the concept of virtual utopia - it is an architectural genre of interactive forecasting of the city of the future where the player creates variable models.

To analyze virtual utopia, we apply to Guy Debord's concept of the Society of the Spectacle (1967), according to which interactivity, variation, and communication in the format of an eternal holiday become the main feature of the world of the future [2]. Guy Debord says that architectural utopia today is possible not as a "static beautiful picture", but as an interactive super-object, a playground for games and actions that involves the architect himself in the immersive process of predicting the city of the future. The virtual utopia reveals the themes analyzed by Umberto Eco (the multiplicity of interpretations, the uncertainty of perception, and the dual nature of the architect as a condition for the existence of an architectural project), as well as the hermeneutical issues raised by Roland Barthes (the generation of meanings, depersonalization, spectator anonymity and the functionality of co-authorship). On the one hand, following Guy Debord and Roland Barthes, virtual utopia "deactivates" the role of an architect in the generally accepted understanding of what he should be (the creator of an ideal picture of the future), on the other hand, he completely "re-imagines" its meaning, making the main character of his own architectural project inside virtual reality. $\mathrm{He}$ becomes the character of a playful architectural utopia, like a citizen of Tommaso Campanella's Civitas Solis (1602) [3]. The value of such personal participation and the involvement of the architect in the creation of a virtual utopia is the feeling of playful importance and responsibility for what is happening, that is, responsibility for the versions of the city of the future that he comes up with, created as living architectural worlds. As the Little Prince would say: "We are responsible for those who have been predicted".

At the same time, it is obvious that the times of architectural manifestos about a single world of the future are over: today utopia lives in the subjective picture of the world of each architect, who has the technical and intellectual capabilities to create an infinite number of options for the future [4]. We can say that architecture has moved away from creating "macro versions" and turned to create "micro versions" of the future. It becomes a space for game processes, the openness of actions (variable "holes" according to Georges Bataille), and the creation of individual options for the future. An architect today strives to come up with a model that is potentially infinitely variable in time and space, which can be transformed in the process of the author's interactive immersion inside his architectural project. Such a situational concept of the architecture of the future (the construction of game variations) cancels its representative function and refers to the experimental and relational forecasting model, which implies the constant interaction of the architect with the surrounding virtual environment. The assumption that architectural utopia has performative rather than predetermined or universal grounds allows the theoretical focus to shift from ideal forms to ways of constructing game parallel models of the future and the multitude of agents involved in this process.

Thus, the architectural utopia of the 21st century opens up the "possibilities of life" (Friedrich Nietzsche), "images-movements" (Gilles Deleuze), it turns into a space of real action, when an architect can literally "share" his imagined version of the city of the future with friends and invite them to "visit" it, get into his own architectural world, thereby complementing it with additional interactivity. Such an architectural utopia can expand the variants of its final versions to infinity, offering many endings instead of one beautiful picture. Its task is not to create an architectural space, but to come up with game situational processes based on the category of timelessness, which allows utopia to go far beyond the simple "completion" of the forecast and imitate "real life". The virtual worlds produced by the players are real worlds, their reality is undeniable, they never end and do not have their result [5].

Through the game the architect endows the virtual component with his own subjectivity, 
turning it into a fictional world with his own invented laws and rules. This idea is clearly demonstrated by the famous phrase in the movie The Matrix (1999) voiced by the boy program to the main character Neo. Its essence is that to break the laws and logic of reality and "bend the spoon with the power of thought", you need to come up with your own rules, and not try to overcome the existing ones: "Do not try to bend the spoon. It's impossible. First, you need to understand the main thing - there is no spoon. " [6], [7]. In this sense, the idea of virtuality can be conceptually correlated with the concept from modern quantum physics about the hypothetical presence in the universe of the mysterious Higgs boson (particles of God), which is theoretically capable of connecting and combining different time moments at the same time ... In other words, it allows us to admit the hypothesis that reality, like the future, can coexist with its parallel versions in an unlimited number of combinations, and we can ourselves choose the one we deem necessary.

The architectural forecasting of the early $21 \mathrm{st}$ century is changing the retroactive function (image of the future) for the proactive function (creating space for live games), becoming a program that always awaits its users. Like Andy Warhol's "factory", whose residents one by one urged them to stand in front of the camera to become "real". The city of the future has become a Hollywood movie set, and the architect has become an actor or even a resident.

\section{GAME AVATAR OF AN ARCHITECT}

Next, we analyze the new function of the architect and his role in the process of interactive game forecasting of the city of the future.

The game avatar is an interactive shell between the architect and the virtual world around him. It brings together the physical and virtual components of an architectural project and allows the player to directly interact with the space of the city of the future.

The concept of a game avatar refers to the idea of a "body without organs" described in The Logic of Sense (1969) by Gilles Deleuze [8]. Initially, it pointed to the "virtual" dimension of the body: the ability to conduct experiments and reveal the virtual potential of your body. A body without organs represents zero intensity, absent stability, virtuality, and unformed matter - it is an "empty body" freely filled with principle-temporal variable organs. The virtualization of corporeality is also present at the heart of Asian mythology, in which organs and various parts of the bodies have their own soul and can be separated at any time from a person, freely traveling the world. The concept of "avatar" is also found in Hinduism, where it means the god Vishnu, descended into the material world from "Vaikuntha" with a specific mission. The virtual body can be traced in modern concepts of "immaterial form art" or "living art" (art vital), which consider the process of "dematerialization" of a character (direct contact, free choice, overcoming boundaries, movement of energy, the impossibility of repetition, impossibility of a previously known end). However, the main analogy of the concept of "body without organs" lies in the field of computer games, where it stands for the concept of "game shell" (skin). This is a symbolic alter-ego of the player in the space of virtual simulation, represented by him there in the form of the main character with his own characteristics and properties. The game shell has a set of certain traits, skills, movements, effects that determine the way the player interacts with the virtual environment.

Themes of human freedom, its existential existence in time, space, and one's own body remain central in the era of virtual reality [9]. A collective and interactive approach to the design of a virtual architectural project, involving two or more architects in the process, refers to the idea of "mimetic desire" by Rene Girard (1961), that is, the desire of one person to take possession of a virtual object, desired by another, and overcome with the help of substitution [10]. The in-game avatar immerses the architectural project in a space of changeability and cancels its isometric, pictorial, and static images on a "sheet of paper". It turns the architect into a "time traveller", helping him to carry out multivariate and interactive forecasting of the city of the future.

\section{Positions:}

- $\quad$ the virtual body becomes the main medium that allows you to visualize and create an architectural space;

- the virtual body is cross-referential, it is a borderline state, a gap between the game and the architect;

- the virtual body uses the game and physical energy of the players as the main ethers to create a virtual city, where the direct participation of other architects with each other is necessary; 
- the virtual body hyperfragments the image of the future, with any interaction multiplies it into an infinite number of parallel realities;

- the virtual body allows the architect to get a gaming experience and live events inside the virtual city.

\section{RETURN OF THE ARCHITECTURAL JEDI. THE DARK AND LIGHT SIDE OF THE POWER}

Researching the interactive game forecasting of the city of the future, the authors propose a new concept - an architectural superhero. The character, whose powers exceed the usual human measure, is one of the constants of the popular imagination: from Heracles to Siegfried, from Roland to Pantagruel, and so on up to Peter Pan. However, in the interpretation of architectural utopia, this definition receives a new connotation.

We propose to divide the concept of an architectural superhero into two conceptual poles: a light and a dark hero. Thus, the authors oppose each other two characters of the architectural utopia of the $21^{\text {st }}$ century. Both modes reveal the idea of interactivity and multi variance in the process of architectural forecasting of the future. Their differences and similarities were revealed in comparison.

The light hero is the image of the player who creates the real space of the city of the future. The dark hero is the image of the player who creates the virtual space of the city of the future.

The article assumes a hypothesis of the inseparability of two opposite models of an architectural superhero in the process of creating an interactive and multivariate architectural utopia of the $21^{\text {st }}$ century. Thus, on one hand, the "dark" side of the architectural superhero allows to reveal the potential of the virtual space and to carry out extreme experiments in the project of the city of the future. On the other hand, an important role is played by the "light" side of the architectural superhero, which makes it possible to measure the concepts invented by him with the real physical world and to adapt virtual experiments in real space. Such an approach can conceptualize the significance of multivariate versions of cities of the future for the real development of the architectural activity of an architect.
It is important to point out that the virtual and the real worlds are in a symbiotic relationship. If the forecasting and design methods already worked well with the real world before, then with the virtual world they fail. The main role has always been played only by the light hero, who leads the game to the end, while the dark one leads the game to unpleasant uncertainty.

A vivid analogy for this idea refers to the images from modern cinema. It is proposed to analyze the universe of Star Wars (1970). This universe is based on two basic postulates. The first one talks about the existence of the so-called Jedi (light) and Sith (dark heroes) in the future world. These characters are endowed with the ability to control supernatural matter - light and dark power. The second talks about the harmonious relationship between the hero and the power itself. The Force is the most important concept in the fantastic epic Star Wars. The Force is described by Obi-Wan Kenobi as "the energy field created by all living beings that surround us is inside us and binds the Galaxy together" [11]. Another character Luke Skywalker says: "Strength is not your ability. It's not about the ability to lift stones. This is the energy of everything, tension, balance. It ties the universe together. "Thus, according to the Star Wars universe, a light or dark hero who knows how to direct the Force can develop abilities for telekinesis, deep hypnosis, supersensible perception, and foresight of the future. Another conceptual analogy that reveals the idea of bipolarity in the architectural utopia of the $21^{\text {st }}$ century is the image from the cinematic universe of Night Watch (2004). This ontology describes the existence of "Others", who, like the Jedi and Sith in "Star Wars", are split into two warring races - dark and light. Dark and Light Watches - organizations created directly to maintain order and balance in the universe between two extreme manifestations of power [11].

The proposed concept of "light and dark power" synergizes with the concepts of the architectural utopia of the 21 st century - virtual and physical reality. Under the concept of "dark power," it's meant "virtuality", which performs similar functions concerning the management of the laws and logic of virtual utopia. The concept of "light power" works with the disclosure of the possibilities of the physical space of the city of the future. The author's appeal to this conceptual image allows revealing the potential of the game multivariate and interactive forecasting of the city of the future, which is guided not only by virtual 
logic but also by the logic of the physical world [12].

Thus, in these presented analogies from modern cinema, we offer as a working hypothesis, the idea of two conceptual manifestations of the architectural utopia of the $21^{\text {st }}$ century in the process of designing the city of the future. The two opposites (light and darkness/reality and virtuality) are considered by the authors not as mutually exclusive versions of the future (utopia and dystopia), but as mutually complementary and revealing the potential of each other immersive and recursive matter. The authors believe that the architectural utopia of the $21^{\text {st }}$ century finds its embodiment in a meta-position, which oscillates two extremes (virtuality and reality), moving from one to the other during the game. In a state of oscillation of two diametrical positions, a "playful architectural utopia" arises. It can be understood as a space between reality and the virtual world. It is this "space between" that is central for the modern architect, who through it carries out interactive and multivariate experiments with the architecture of the future.

To describe such a "space between", the author refers to the concept of "Twilight", described in the previously mentioned universe of Night Watch. According to its basic meaning, "Twilight" is the mysterious structure in the ontology of the universe, which balances the two worlds. On the one hand, this is the territory of the Others, the environment in which they can live. On the other hand, it is a way of measuring the strength of Others, since its structure is layered. Each further immersion on a new layer of "Twilight" requires more and more power, and if most of the Others have access to only the second layer, then the third and fourth layers are open only to the highest Others - magicians of the first category and above. The mechanics of entering the "Twilight" is similar in its structure to the mechanics of entering virtual reality and then exiting it back and can be described as a process of subtraction [11]. Also, "Twilight" can be interpreted in the categories of "fold" of Gilles Deleuze: it is determined by opposing forces, each is trying to gain the upper hand over the other [13]. It is "gap", "void", space "between" or continuous bending, like a Mobius strip. Based on this, "Twilight" is a kind of error, a small glitch in a computer program, through which, for a moment you can see two realities: virtual and real. As in the mysterious "zone" in the film The Anti-Matrix (2003), where it rains and does not fall at the same time, morning and night begin, and a person, falling from a great height, suddenly freezes a millimetre from the surface. This is a game space where the logic of the virtual and physical worlds coexists.

Thus, is given an understanding of the basic components of a game architectural utopia and a multivariate forecast of the future:

- the light hero (the register of the architect, when he operates with the real space of the city);

- dark hero (architect's register when he operates the virtual space of the city)

- light power (reality);

- dark power (virtuality);

- dusk (architectural border between real and virtual space);

- game architectural utopia (the final project of a multivariate city of the future, which uses the interactive potential of real and virtual space during the design process).[14]

\section{CONCLUSION}

Summarizing the findings of this article, we believe that time is linear. That it flows constantly and evenly to infinity. But the difference between Past, Present, and Future is just an illusion. Yesterday, Today, and Tomorrow are inconsistent. They are linked in an endless game. Everything is interchangeable.

Until that time, we tried to draw a "static" ideal version of the future, however, today architectural science admits elements of collectivity, simulation, customization, incompleteness, and variance into the forecasting process. With the emergence of a new type of architectural utopia, new questions arise: "How can I live in your architectural reality? How does the meeting of two architectural realities change both? What kind of process allows the city of the future to change endlessly and not have a final decision?

\section{AUTHORS' CONTRIBUTIONS}

The authors of this article work in the Department of Architecture in the direction of the Design of the architectural environment. Egor Orlov is working on his Ph.D. thesis on the evolution of architectural utopias, and his area of professional interests includes searching for alternative models of game forecasting of the City of the future. Anna Solovieva and Tatiana 
Semichevskaya are testing architectural innovations in practice in the VR laboratory of RUDN University. The main contribution of the authors to the theory of modern architecture can be considered as an attempt to give a conceptual description of a new model of the game forecast of the City of the future. This approach is based on the idea of liveaction - a person plays into the future and does not predict it. Thus, the player does not seek to create one single beautiful version of the future but comes up with a living interactive world.

\section{REFERENCES}

[1] L. Mantash, M. Youssef, Exploring utopian representations in the architecture of art museums in the middle east. Advances in Science, Technology and Innovation, 2021, pp. 105-125. URL: https://link.springer.com/chapter/10.1007\%2F 978-3-030-50765-7_10

[2] G. Debord, The Society of the Spectacle (Obshchestvo spektaklia), Opustoshitel', Moscow, 2011 [in Russian]. URL: http://vcsi.ru/files/gi_debor.pdf

[3] L. C. Pearson, System cities: Building a 'quantitative utopia Architectural Design, Willey Online Library, 89 (4) (2019) 70. URL:

https://onlinelibrary.wiley.com/doi/abs/10.100 2/ad.2459

[4] A. Sadrieva, NOT (manifest) (NE (manifest)), Tatlin, Moscow, 2018 [in Russian]. URL: https://tatlin.ru/articles/nemanifest

[5] E. Kharitonov, Apocrypha through the looking glass (Etudes about fiction) (Apokrify zazerkal'ia (Etyudy o fantastike)). Group of companies "AURAINFO \& GROUP MFA", St. Petersburg, 2020 [in Russian]. URL: https://fantlab.ru/blogarticle69559

[6] V. Shlykov, Philosophical fiction: from the Strugatskys to the "Matrix" (Filosofstvuyushchaia fantastika: ot Strugatskikh do "Matricy"), Group of companies "AURAINFO \& GROUP MFA", St. Petersburg, 2019, pp. 272 [in Russian]. URL: https://fantlab.ru/work1239226?sort=date

[7] Criticism of the digital mind (Kritika tsifrovogo razuma), Academy for Cultural
Research, St. Petersburg, 2020, pp. 295 [in Russian].

[8] G. Deleuze, The Logic of Sense (Logika smysla), Academic project, Moscow, 2015, pp. 264 [in Russian]. URL: https://platona.net/load/knigi_po_filosofii/post modernizm/deljoz_zh_logika_smysla/54-1-01940

[9] S. Shikarev, Science fiction coordinates (Koordinaty fantastiki), Group of companies "AURAINFO \& GROUP MFA", St. Petersburg, 2019, pp. 320 [in Russian]. URL: https://fantlab.ru/edition241590

[10] R. Girard, Romantic Lie and Romanesque Truth (Lozh' romantizma i pravda romana), "New literary review", Moscow, 2019 [in Russian].

URL: https://kindbook.net/kniga/lozh-romantizma-ipravda-romana-zhirar

[11] N. Sazonov, Parasitic Jedi (Parazitiruyushchii dzhedai), philosophical and literary journal "Logos" (5) 2019 265-282 [in Russian]. DOI: 10.22394/0869-5377-2019-5-265-280 http://www.logosjournal.ru/arch/108/Logos.20 19_5(132)\%20(1)-271-288.pdf

[12] K. Cytlak, Prospective architecture in Czechoslovakia. Convergences and divergences between the approach of the Slovak group VAL (1968-1994) and the architectural theory of Michel Ragon L'architecture prospective en Tchécoslovaquie, RIHA Journal 0179 (2017). URL: https://journals.ub.uniheidelberg.de/index.php/rihajournal/article/vie w/70264

[13] G. Deleuze, The Fold: Leibniz and the Baroque (Skladka. Leibnits i barokko), Logos, Moscow, 1998 [in Russian]. URL: http://yanko.lib.ru/books/philosoph/deleuze\% 3Dle_pli\%3Dleibniz_et_le_baroque.pdf

[14] A. Gerber, U. Götz (eds.), Architectonics of Game Spaces. The Spatial Logic of the Virtual and Its Meaning for the Real, Funded by: Kollektion-Knowledge Unlatched Auswahl 2019 FL and Knowledge Unlatched - KU Select 2019, Frontlist Collection transcriptVerlag, Bielefeld, 2020. DOI: https://doi.org/10.14361/9783839448021 